\title{
SST-Wind Interaction in Coastal Upwelling: Oceanic Simulation with Empirical Coupling
}

\author{
Xin Jin, Changming Dong, Jaison Kurian, and James C. McWilliams \\ Institute of Geophysics and Planetary Physics, University of California, Los Angeles, Los Angeles, California \\ Dudley B. Chelton \\ College of Oceanic and Atmospheric Sciences, Oregon State University, Corvallis, Oregon
}

ZHIJIN LI

NASA Jet Propulsion Laboratory, Pasadena, California

(Manuscript received 24 December 2008, in final form 28 April 2009)

\begin{abstract}
Observations, primarily from satellites, have shown a statistical relationship between the surface wind stress and underlying sea surface temperature (SST) on intermediate space and time scales, in many regions inclusive of eastern boundary upwelling current systems. In this paper, this empirical SST-wind stress relationship is utilized to provide a simple representation of mesoscale air-sea coupling for an oceanic model forced by surface winds, namely, the Regional Oceanic Modeling System (ROMS). This model formulation is applied to an idealized upwelling problem with prevailing equatorward winds to determine the coupling consequences on flow, SST, stratification, and wind evolutions. The initially uniform wind field adjusts through coupling to a cross-shore profile with weaker nearshore winds, similar to realistic ones. The modified wind stress weakens the nearshore upwelling circulation and increases SST in the coastal zone. The SST-induced wind stress curl strengthens offshore upwelling through Ekman suction. The total curl-driven upwelling exceeds the coastal upwelling. The SST-induced changes in the nearshore wind stress field also strengthen and broaden the poleward undercurrent. The coupling also shows significant impact on the developing mesoscale eddies by damaging cyclonic eddies more than anticyclonic eddies, which leads to dominance by the latter. Dynamically, this is a consequence of cyclones with stronger SST gradients that induce stronger wind perturbations in this particular upwelling problem and that are therefore generally more susceptible to disruption than anticyclones at finite Rossby number. The net effect is a weakening of eddy kinetic energy.
\end{abstract}

\section{Introduction}

Analyses of observations have consistently demonstrated a significant statistical relationship between the curl and divergence of surface wind stress and the underlying gradient of sea surface temperature (SST) where it is relatively strong (see review by Small et al. 2008). The proximate explanation is that SST gradients induce gradients in lower-atmospheric stratification; hence, gradients in vertical momentum flux in the atmospheric boundary layer and gradients in the surface wind stress

Corresponding author address: Dr. Xin Jin, IGPP, University of California, Los Angeles, 405 Hilgard Avenue, Los Angeles, CA 90095-1567.

E-mail: xjin@ucla.edu beneath an otherwise more uniform midtropospheric wind are induced. This yields apparently linear relationships between the wind stress curl and divergence and the crosswind and downwind components of the local SST gradient (Chelton et al. 2004). The relationship was first shown clearly in the eastern tropical Pacific Ocean with measurements of the surface wind stress from the Quick Scatterometer (QuikSCAT) and SST from the Tropical Rainfall Measuring Mission Microwave Imager (Chelton et al. 2001); with particular relevance to the present paper, it was further confirmed by a recent study in the upwelling frontal zone along the U.S. West Coast (Chelton et al. 2007a).

Ocean-atmosphere interaction involves two processes: SST modification of the dynamics in the atmospheric boundary layer and feedback of this modification to the 
ocean currents through the surface stress. Mechanisms for the first process, the wind response to oceanic SST gradients, have been investigated extensively. Lindzen and Nigam (1987) used a one-dimensional atmospheric boundary layer model to study the surface wind response to tropical instability waves in the eastern equatorial Pacific Ocean. They suggested that the wind field is characterized by the horizontal pressure gradient developed in response to the boundary layer baroclinicity induced by the underlying SST gradient.

The coupled feedback on the ocean has only begun to be studied. Spall (2007) has shown that the feedback from winds blowing across SST fronts modifies the growth rate and wavelength of baroclinically unstable waves. Chen et al. (2003) coupled the Lindzen and Nigam (1987) model with an oceanic model to study shelf-break frontogenesis and showed a positive feedback that locally strengthened both the wind and the front. Perlin et al. (2007) found that the SST in a coastal upwelling regime was lower near the coast after several days using a coupled atmosphere-ocean mesoscale model.

In this study, we take advantage of the empirical relationship between the SST gradient and wind stress in place of a dynamical atmosphere and couple it to a regional oceanic model. With the background wind stress field modified by the evolving SST field and used to force the ocean concurrently, an air-sea coupling process is built into the model. In this scheme, the surface heat flux is not altered by the coupling, although it may be an important component of this air-sea interaction phenomenon (Haack et al. 2008). We apply this empirical coupled model to a geographically idealized coastal upwelling system that is integrated for many months, until it reaches a statistical equilibrium with associated mesoscale fronts, filaments, and eddies. The numerical model and configuration and the implementation of the SSTwind stress coupling algorithm are described in section 2 . The uncoupled upwelling circulation is analyzed in section 3, and the coupled model results are presented in section 4 . We summarize our findings in section 5 .

\section{Methodology}

\section{a. Oceanic model}

To implement and test the empirical model of the twoway coupling between the surface SST and the surface wind stress, we developed an idealized numerical configuration using the Regional Oceanic Modeling System (ROMS). It solves the rotating primitive equations in a split-explicit, free-surface oceanic model, where short time steps are used to advance the surface elevation and barotropic momentum equations, with a larger time step used for temperature, salinity, and baroclinic momen- tum (Shchepetkin and McWilliams 2005). A third-order, upstream-biased advection operator allows the generation of steep gradients in the solution, enhancing the effective resolution of the solution for a given grid size (Shchepetkin and McWilliams 1998). K-profile verticalmixing parameterizations are used for surface and bottom boundary layers (Large et al. 1994). ROMS has been successfully used for many problems, including circulations on different scales of the coastal upwelling system of the U.S. West Coast (Marchesiello et al. 2003; Capet et al. 2004; Dong and McWilliams 2007; Capet et al. 2008).

In the present configuration, the bottom topography is flat with uniform water depth at $500 \mathrm{~m}$ to avoid topographic complexity. A rectangular domain is used with a straight coastline to the east, which is comparable to the central California coast. The domain size spans $960 \mathrm{~km}$ in the north-south direction and $800 \mathrm{~km}$ in the west-east direction. A background uniform wind stress $\tau^{*}$ with an amplitude of $0.07 \mathrm{~N} \mathrm{~m}^{-2}$ blows equatorward constantly. The alongshore pressure gradient is one of the primary driving forces for the poleward undercurrent and surface Davidson Current along the U.S. West Coast (e.g., Hickey and Pola 1983; Chelton 1984; Dong and Oey 2005). To incorporate an alongshore pressure gradient into this idealized system, a periodic condition on the northern and southern open boundaries cannot be used [although periodic conditions are sometimes used to study the upwelling system (e.g., Gan and Allen 2005)]. Instead, initial and open boundary conditions are applied (Marchesiello et al. 2001) by using the temperatures and the normal components of the Ekman and geostrophic currents along the open boundary. These fields are estimated based on a typical upwelling system profile along California.

The initial alongshore-averaged, cross-shore $T(x, z)$ profile and its associated geostrophic alongshore current are shown in Fig. 1; a level of no motion is assumed for the model base at $H=500 \mathrm{~m}$. In addition, there is a decreasing temperature and sea level elevation from south to north with alongshore-uniform gradients and net depth-averaged magnitudes of $1^{\circ} \mathrm{C}$ and $7 \mathrm{~cm}$, respectively; these meridional gradients induce a geostrophic cross-shore current. For simplicity, the salinity is set to be a constant $35.00 \mathrm{psu}$, so that the density is solely determined by temperature. The Ekman current is specified from the background meridional surface stress, which is uniform over the domain, and it has a slab mixed-layer structure with a depth of $h_{e}=40 \mathrm{~m}$; hence, $u_{e}=\tau_{y}^{*} /\left(\rho_{w} h_{e} f\right)$, where $f$ is the mean Coriolis frequency for this domain. The horizontal grid size is $2 \mathrm{~km}$, and there are 30 vertical levels with layer-thickness values from $\sim 2 \mathrm{~m}$ at the surface to $\sim 50 \mathrm{~m}$ at the bottom. A quadratic bottom stress with a drag coefficient of 

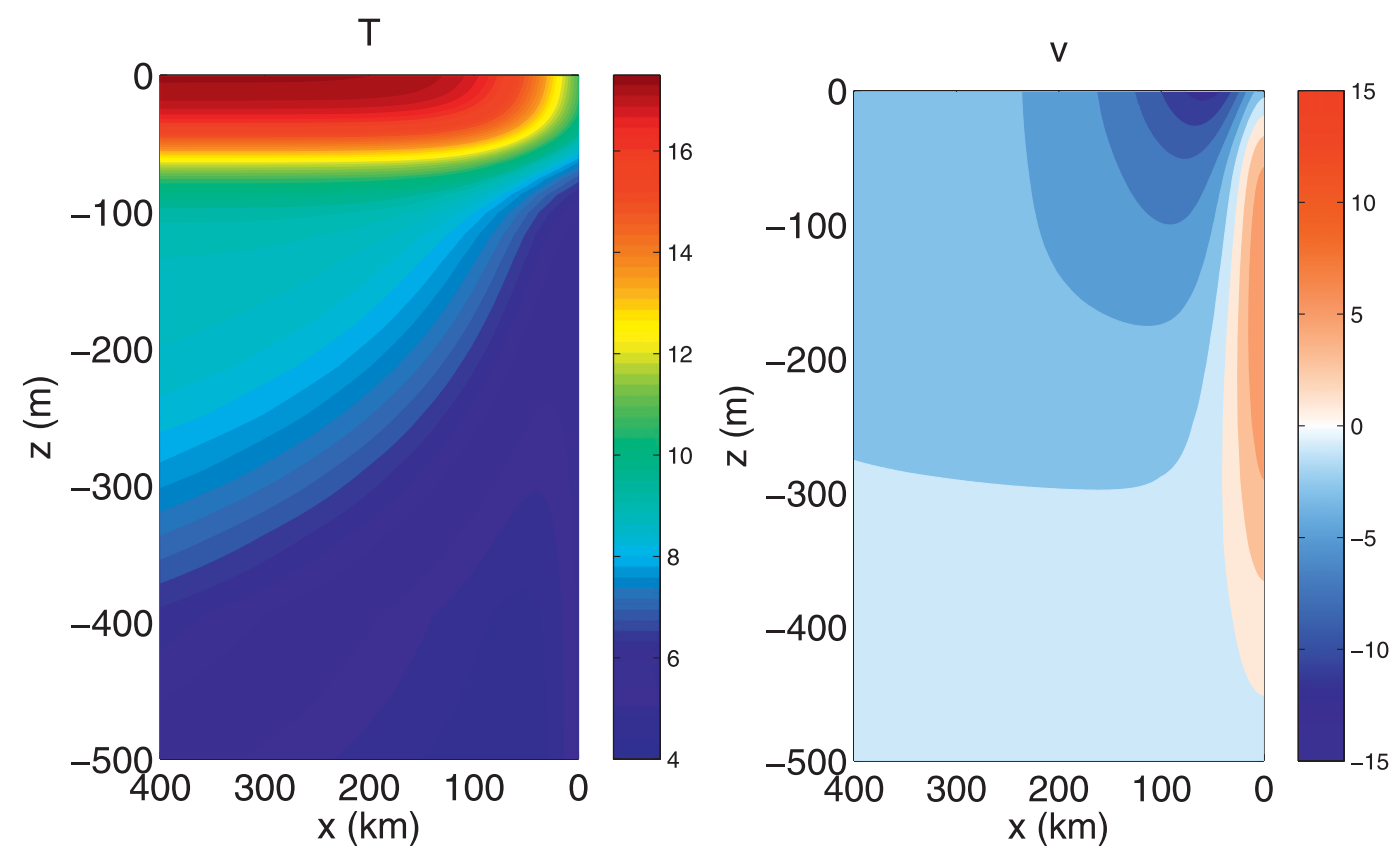

FIG. 1. Initial cross-shore sections of alongshore-averaged $T\left({ }^{\circ} \mathrm{C}\right)$ and $v\left(\mathrm{~cm} \mathrm{~s}^{-1}\right)$ for both coupled and uncoupled cases.

$3.0 \times 10^{-4} \mathrm{~m} \mathrm{~s}^{-1}$ is included, but it has relatively little influence on the solution.

\section{b. Empirical coupling relations}

Except possibly in the very nearshore region, the influence of SST on surface winds over the California Current System (CCS) is well represented in the U.S. Navy Coupled Ocean-Atmosphere Mesoscale Prediction System (COAMPS) model run in a one-way coupled configuration (Haack et al. 2008). The results of a two-way coupled model of the California Current System have been presented by Seo et al. (2007). Although this fully coupled model produced realistic patterns of the surface wind stress response to SST, the coupling between the wind stress and SST was underestimated by a factor of 5-10. As a consequence, it can be expected that the feedback effects of the SST-induced perturbations of the wind stress field on the circulation in the California Current System are underestimated. The objective of this study is to assess the significance of the feedback effects that can be expected from a two-way coupled model that accurately reproduces the surface wind response to SST. This is investigated by analyzing the responses of the surface wind stress field and the ocean circulation after imposing an empirically based coupling between SST and surface wind stress.

The empirical coupling procedure can be summarized as follows: given a background surface wind stress field $\tau^{*}=\left(\tau_{x}^{*}, \tau_{y}^{*}\right)$ that is either specified a priori (as here) or taken from a meteorological analysis, we compute a modified wind stress $\tilde{\tau}$ based on empirical coupling relations for wind stress curl $Z$ and divergence $\Delta$ in response to SST gradients (Chelton et al. 2007a). A Helmholtz decomposition of the $2 \mathrm{D}$ wind stress field is

$$
\tau=\hat{\mathbf{z}} \times \nabla \Psi+\nabla \chi,
$$

where $\Psi$ and $\chi$ are the streamfunction and divergent wind stress potential fields, respectively. The curl and divergence fields are

$$
\begin{aligned}
& Z=\hat{\mathbf{z}} \cdot \nabla \times \boldsymbol{\tau}=\nabla^{2} \Psi \text { and } \\
& \Delta=\boldsymbol{\nabla} \cdot \boldsymbol{\tau}=\nabla^{2} \chi .
\end{aligned}
$$

Within a closed domain, $\tau$ and its $(\Psi, \chi)$ decomposition are determined from (1) by solving the Poisson Eqs. (2) and (3) for given $Z$ and $\Delta$ fields and wind stress at the boundary $\tau_{b}$. This boundary-value problem can be viewed as an inverse problem (Kirsch 1996; Tikhonov and Arsenin 1977) that can be solved reliably using Tikhonov's regularization. Li et al. (2006) implemented the regularized Tikhonov minimization procedure in the ROMS model. For our configuration, we give a brief description of the procedure as follows: the discrete version of Eqs. (2) and (3) can be written as a linear system of the form 


\section{COOL}

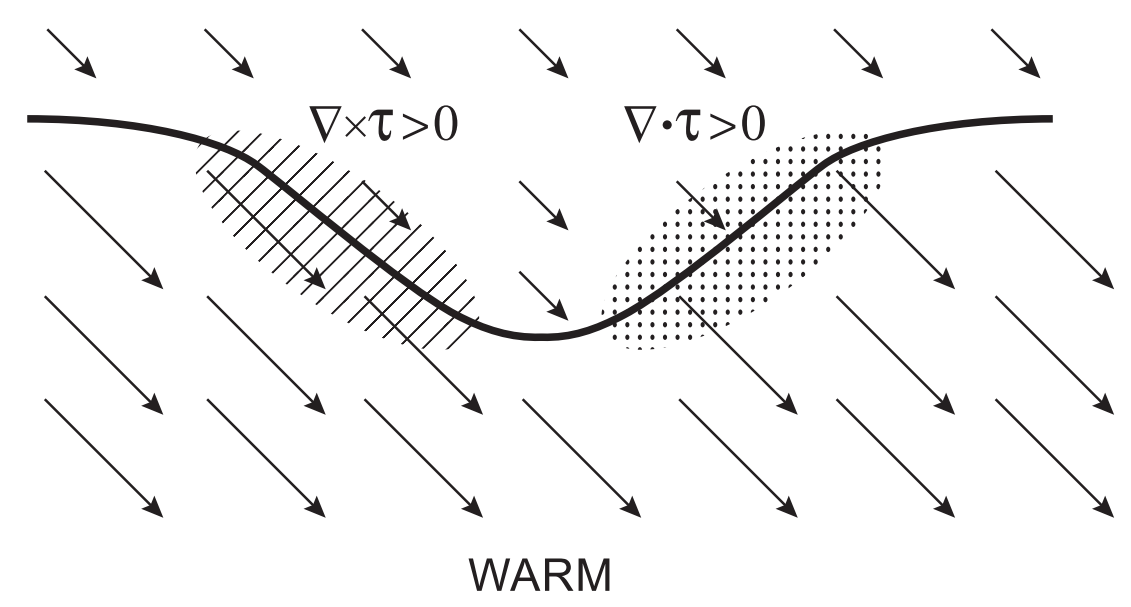

$$
\nabla \times \tau \sim \underbrace{\nabla S S T \times \hat{\tau}=|\nabla S S T| \sin \theta}_{\text {Crosswind SST Gradient }}
$$

$$
\nabla \cdot \tau \sim \underbrace{\nabla S S T \cdot \hat{\tau}=|\nabla S S T| \cos \theta}_{\text {Downwind SST Gradient }}
$$

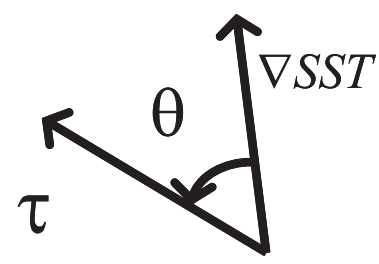

FIG. 2. Sketch of the empirically determined linear relationships between wind stress curl and divergence and the local crosswind and downwind components of SST gradient (adapted from Moloney and Chelton 2006).

$\mathbf{y}=\mathbf{A x}, \quad$ where

$$
\mathbf{y}=\left(\begin{array}{c}
Z \\
\Delta
\end{array}\right), \quad \mathbf{x}=\left(\begin{array}{c}
\tau_{x} \\
\tau_{y}
\end{array}\right) .
$$

The matrix A depends on the spatial discretization scheme. Then, the objective function to be minimized includes a penalty for departures from (2) and (3), as well as a penalty for departures of the stress from the background field:

$$
J(\mathbf{x})=\frac{1}{2}(\mathbf{y}-\mathbf{A x})^{\mathrm{T}}(\mathbf{y}-\mathbf{A x})+C(d)\left(\boldsymbol{\tau}-\boldsymbol{\tau}^{*}\right)^{2},
$$

where the superscript $\mathrm{T}$ stands for transpose. The regularization parameter $C(d)$ is designed as a function of the offshore distance $C(d)=1+7.5\{1+\tan h[(d-$ $\left.\left.\left.d_{\max }\right) / 40\right]\right\}$, and $d_{\max }=400 \mathrm{~km}$. The larger offshore values assure that $\tau \rightarrow \tau^{*}$ away from the coast, where the SST fluctuations vanish; hence, $Z, \Delta \rightarrow 0$ by the empirical coupling relations. The small onshore values leave the stress free to evolve away from $\tau^{*}$ near the coast, where upwelling and SST variability are strong. A boundary condition is not explicitly specified, but the solution of the minimization problem enforces the normal derivatives of both streamfunction and velocity potential to approximately satisfy the decomposition given in (1) at the boundary.

The Tikhonov regularization guarantees a unique solution of the minimization problem. Without the regularization, the minimization problem is undetermined with respect to additive constants in both potential function and in general has an unlimited number of solutions. Because $\hat{Z}$ and $\hat{\Delta}$ depend on wind direction, there needs to be an iterative cycling until convergence. When the cycle converges, the obtained solution is close to the one with the regularization, especially in the present circumstances where the regularization parameter is chosen to be small. Thus,

$$
\begin{aligned}
& \tilde{Z}_{i+1}=\tilde{Z}_{i}+\alpha\left(\hat{Z}-\tilde{Z}_{i}\right) \text { and } \\
& \tilde{\Delta}_{i+1}=\tilde{\Delta}_{i}+\alpha\left(\hat{\Delta}-\tilde{\Delta}_{i}\right),
\end{aligned}
$$

using the empirical coupling relations (Fig. 2),

$$
\begin{aligned}
& \hat{Z}=\nabla \times \boldsymbol{\tau}=c_{1}|\nabla S S T| \sin \left(\theta_{i}\right) \quad \text { and } \\
& \hat{\Delta}=\nabla \cdot \boldsymbol{\tau}=c_{2}|\nabla S S T| \cos \left(\theta_{i}\right),
\end{aligned}
$$




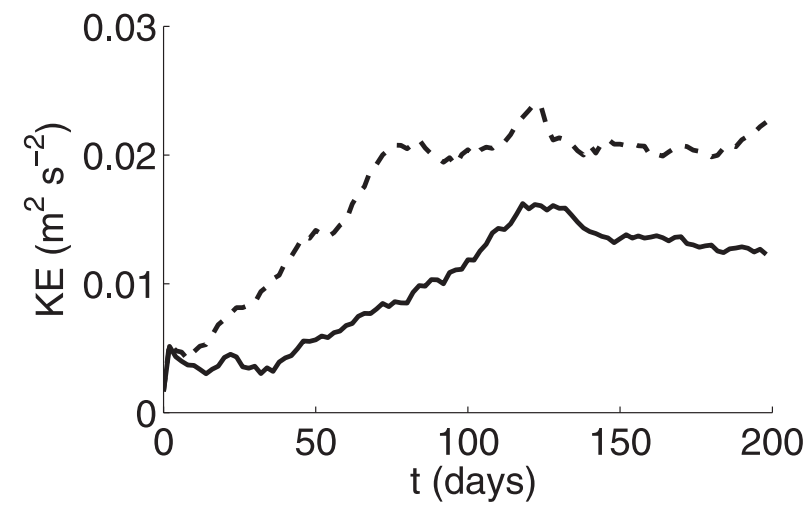

FIG. 3. Area-averaged surface KE, $1 / 2\left(u^{2}+v^{2}\right)$. Dashed and solid lines are for uncoupled and coupled cases, respectively. The initial $\mathrm{KE}$ value is $0.0016 \mathrm{~m}^{2} \mathrm{~s}^{-2}$.

where the subscript $i$ refers to the iteration cycle and $\tilde{Z}_{1}=Z^{*}$ and $\tilde{\Delta}_{1}=\Delta^{*}$, which are computed from $\tau^{*}$. Values of $c_{1}=0.0166$ and $c_{2}=0.0222 \mathrm{~N} \mathrm{~m}^{-2}{ }^{\circ} \mathrm{C}^{-1}$ are estimated for the California Current System $\left(35^{\circ}-45^{\circ} \mathrm{N}\right.$, $128^{\circ}-120^{\circ} \mathrm{W}$ ) with temporal smoothing with a 15 -day halfpower filter cutoff and spatial smoothing with $\sim 75 \mathrm{~km}$ half-power filter cutoff (cf. Chelton et al. 2007a). The term $\theta_{i}$ is the counterclockwise angle from the SST gradient $\nabla$ SST toward the wind direction $\hat{\mathbf{e}}_{i}$. From $\tilde{Z}, \tilde{\Delta}$, we compute the modified $\tilde{\tau}$ by the Tikhonov procedure. The term $\alpha$ is a nondimensional iteration relaxation parameter to assist convergence, and we find that 0.2 is a useful value. The operational convergence criterion is $\leq 5 \%$ in the relative difference between successive iterates in the wind stress.

In the empirical coupled ROMS model, we replace the background value of $\boldsymbol{\tau}^{*}$ with $\tilde{\tau}$ to include the effect of time-evolving SST. The wind modification is done with a 2-h interval, because the SST does not change appreciably on a shorter time scale. A posteriori, we verify that the wind stress can be iterated to satisfy (8) and (9) to a correlation level in excess of 0.995 in our coupled solutions, verifying the accuracy of our procedure.

\section{Uncoupled upwelling circulation}

From the initial condition defined in section 2 and Fig. 1, the oceanic model is integrated for 240 days with the background constant wind stress (i.e., without air-sea coupling). The evolution is illustrated with a time series of surface kinetic energy (KE; Fig. 3). There is a quick adjustment to accommodate the shoreline boundary condition and initiate the upwelling circulation within the first few days, followed by a steady energy growth until equilibrium sets in around day 75 . With the constant equatorward wind blowing over the stratified ocean, the westward Ekman transport moves upper-layer water off the coast, the lower cold and dense water is pumped to the surface, and an upwelling SST front forms around day 10. With continuing development of the SST front and associated alongshore geostrophic flow, a baroclinic instability occurs along the front, with associated incipient mesoscale eddies and filaments (Fig. 4a). SST varies by $\sim 10^{\circ} \mathrm{C}$ from the coast to $200 \mathrm{~km}$ offshore. In the equilibrium phase, the eddy field reaches beyond $300 \mathrm{~km}$ from the coast, and there are evident coherent cyclonic and anticyclonic vortices (see Fig. 9).

Cross sections of the mean flow and stratification (Figs. 5, 6) show the expected upward thermocline tilt, southward surface flow with a maximum speed of $15 \mathrm{~cm} \mathrm{~s}^{-1}$, and northward undercurrent against the coast with its maximum between 100-200 m depth. The mean zonal flow has a shallow offshore Ekman transport above a general subsurface shoreward flow to a depth of around $300 \mathrm{~m}$, with mostly upward vertical velocity within about $100 \mathrm{~km}$ of the coast and peaked close to the boundary. All of these characteristics in this idealized configuration are similar to those in simulations with realistic geography and forcing (Marchesiello et al. 2003).

\section{SST-wind interaction effects}

The coupled model was run for 240 days from the same initial condition. In addition, we have run two experiments with half (HALF) and double (DBL) the values for the coupling coefficients $c_{1}$ and $c_{2}$ in (8) and (9), respectively, to investigate the sensitivity of their estimation to uncertainties. Overall, the coupling effects are qualitatively similar in all three coupled cases, (e.g., Fig. 7) with magnitudes increasing with the coefficients.

\section{a. Wind stress change}

The structure and dynamical control of the transition profile-from strong marine to weaker terrestrial winds across eastern continental margins-is an unresolved issue in atmospheric modeling, and oceanic responses are sensitive to this transition shape (Capet et al. 2004). The alongshore mean wind stress changes substantially in the coupled simulations and creates a transition profile. The stress magnitude decreases dramatically toward the coast, from $0.07 \mathrm{~N} \mathrm{~m}^{-2}$ offshore to about $0.02 \mathrm{~N} \mathrm{~m}^{-2}$, and it is close to the uniform background wind offshore (Fig. 7, left). The mechanism for the change is clear from the coupling relation (8): cold nearshore SST and alongshore wind make a positive wind stress curl that leads to shoreward reduction in the nearshore wind stress.

The nearshore decrease of the alongshore wind stress has been noticed by other researchers in the coastal upwelling systems. For example, Dorman et al. (2006) 

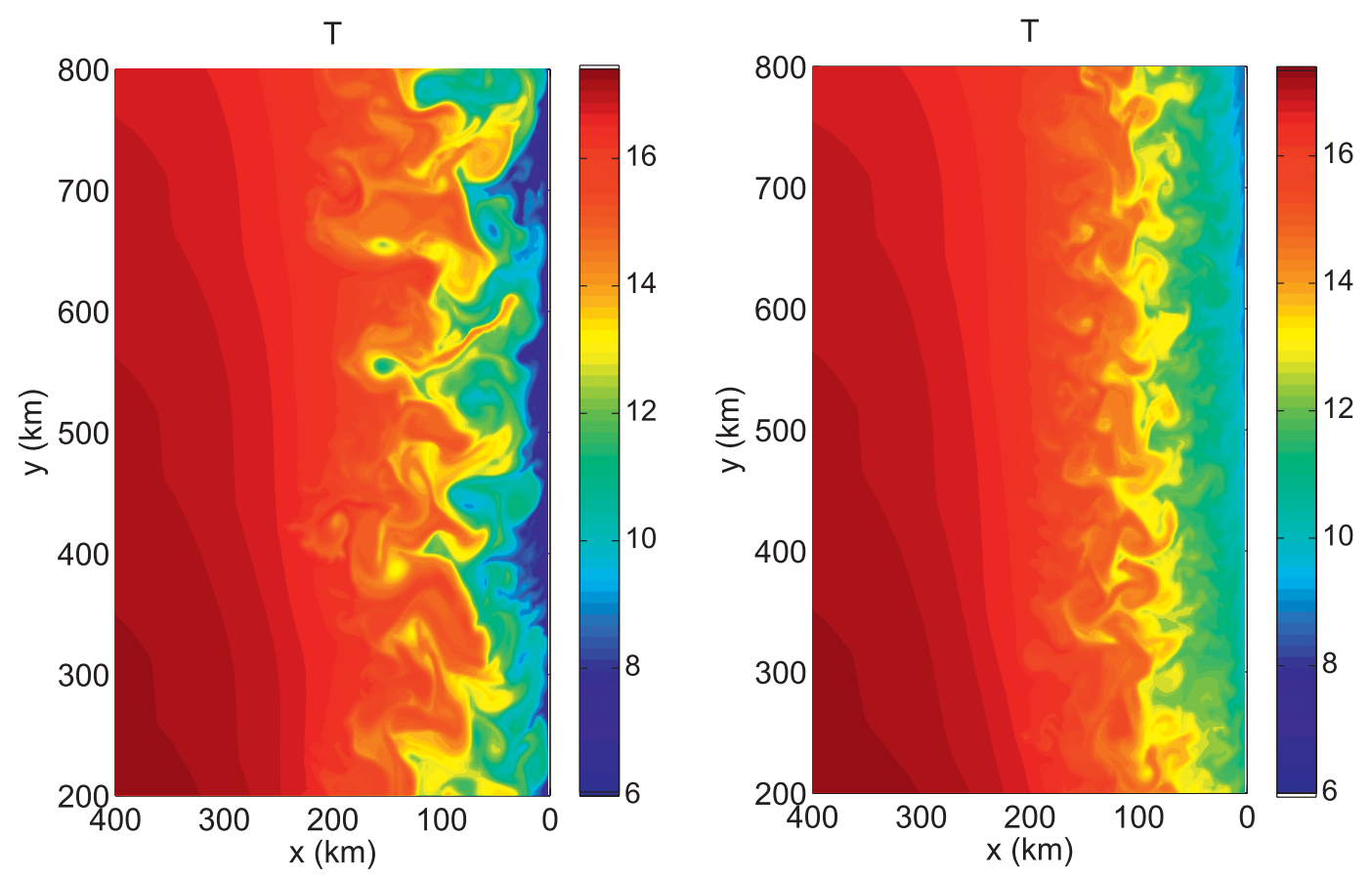

FIG. 4. SST distribution on day 60: (left) uncoupled and (right) coupled.

showed from measurements that the summer-mean alongshore wind stress over the shelf off Bodega Bay, California, decreases from $0.14 \mathrm{~N} \mathrm{~m}^{-2}$ at $25 \mathrm{~km}$ offshore to $0.04 \mathrm{~N} \mathrm{~m}^{-2}$ at $2 \mathrm{~km}$. Perlin et al. (2007) found that the wind stress decreases from 0.14 to $0.075 \mathrm{~N} \mathrm{~m}^{-2}$ near the coast after $72 \mathrm{~h}$ in a coupled mesoscale atmosphereocean model. The mechanism for the broad nearshore region of strong wind stress curl in the CCS resulting from SST-wind coupling was hypothesized by Chelton et al. (2007a).

The sensitivity experiments that double and halve the empirical coupling coefficients show modest impacts on the wind stress changes (Fig. 7), although the SST changes are larger. Thus, the overall effect of the coupling is somewhat less than implied by the linear relations (8) and (9), indicating a negative feedback in the coupled system response. This is likely because the nearshore reduction of upwelling, accompanied by an SST warming, cannot proceed beyond a limit set by an actual wind reversal. In addition to these changes in the mean wind stress, there are transient wind effects on the eddy scale (section $4 \mathrm{c}$ ).

\section{b. Circulation and stratification changes}

The wind stress near the coast is reduced by coupling, hence the SST is less cold, so the geostrophic alongshore current and its instability are initially weaker in the coupled case. This is evident in the lag in surface kinetic energy (Fig. 3) with coupling during its growth phase (days 10-100). It is also evident in the instantaneous SST on day 60 (Fig. 4) where the fluctuations are at an earlier phase in their unstable development. In addition, in the equilibrium phase (days 100-200), the energy is smaller because of the coupling.

The mean stratification and circulation (Figs. 5, 6) show coupling influences through a weaker thermocline tilt resulting from weaker nearshore wind stress. They have an increased poleward transport, especially in the undercurrent, which is consistent with increased coastal wind stress curl and Sverdrup balance. The Ekman circulation in the zonal plane has weaker upwelling right at the boundary with stronger upwelling offshore (Fig. 8). In the faroffshore region away from the upwelling circulation and eddies, the zonal transport in the surface layer approaches the Ekman value for the background wind stress $-\tau^{* y} / \rho_{w} f$ ( $\rho_{w}$ is the mean seawater density and $f$ is the mean Coriolis frequency for this domain) that, in turn, is equal to the integrated upwelling in the shoreward zone. Furthermore, in the coupled simulation, more than half $(\approx 65 \%)$ of the net upwelling occurs as Ekman suction rather than nearboundary upwelling. The simple Sverdrup balance here for the alongshore barotropic current might be modified in coastal regions with strongly sloping topography (e.g., Estrade et al. 2008; Welander 1957).

\section{c. Eddy changes}

The empirical coupling also has a significant impact on the eddy field (Fig. 9). During the equilibrium phase the nearshore eddies are weaker with coupling, because the 

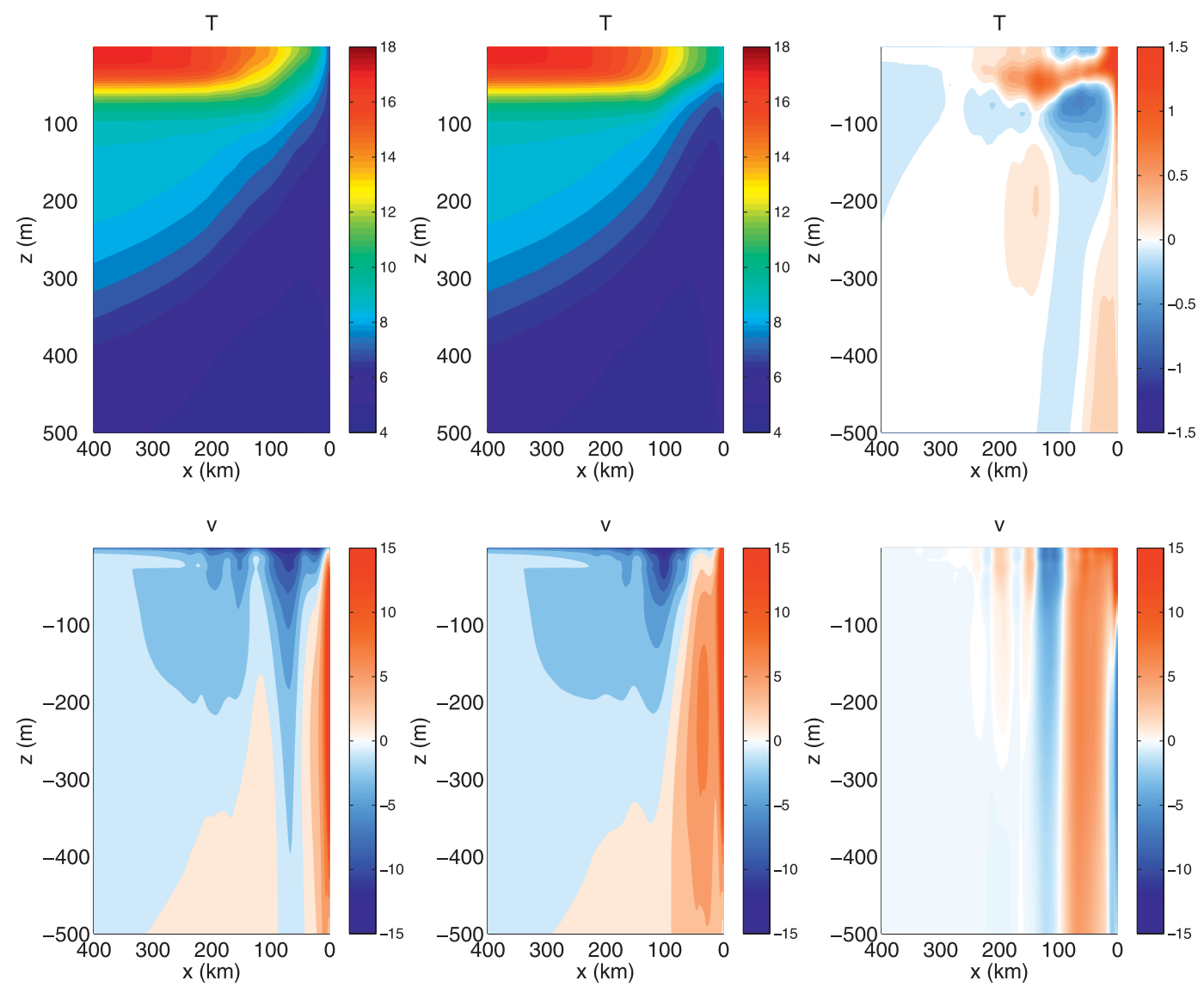

FIG. 5. Cross-shore sections of $T\left({ }^{\circ} \mathrm{C}\right)$ and $v\left(\mathrm{~cm} \mathrm{~s}^{-1}\right)$ averaged alongshore and between days 40 and 80: (left) uncoupled, (middle) coupled, and (right) their difference.

mean upwelling front and alongshore current are farther offshore, and a marked asymmetry develops between well-formed anticyclones and deformed cyclonic vorticity patches. There is a $25 \%$ smaller eddy kinetic energy (EKE) during the equilibrium phase with coupling (Fig. 3). Because coupling reduces the nearshore wind, therefore reducing upwelling, which reduces alongshore velocity and shear, it should also reduce the eddy generation rate by baroclinic instability, which is consistent with the lower EKE in the coupled case. In addition, the weakening of the cyclonic eddies (demonstrated next) also contributes to the lower EKE.

Spall (2007) shows that baroclinically unstable currents can have their linear growth behavior modified by a cross-current wind because of the same type of coupled feedback we include in our model. We checked for this in our coupled solutions and found that there is negligible correlation between the vertical velocity of the growing fluctuations and the wind curl fluctuations induced by the unstable SST fluctuations expected to force vertical velocity through Ekman pumping. This is primarily because the mean wind stress is along the axis of the mean current in the coastal upwelling configuration; hence, coupled wind curl fluctuations develop athwart the current, rather than along it, as required for effective feedback on the unstable mode.

We quantify the eddy properties with an eddy detection algorithm (appendix). This is the basis for the probability density functions (PDFs) over the eddy-interior regions (Fig. 10) and for the eddy properties averaged over the populations (Table 1). In the uncoupled solution, the mature eddy field has somewhat more abundant and stronger cyclones than anticyclones, although the population differences are not enormous by most measures. A very striking difference, however, is in the eddy SST and SST gradients that are much stronger for cyclones by about a factor of 3 on average and associated with a much longer tail in the SST PDF. We have no general explanation for why cyclones are modestly favored in the particular uncoupled upwelling problem we have posed here, although it probably is related to the mean alongshore shear profiles and their instability properties. However, we do understand their much stronger cold SST signal from hydrostatic, gradient-wind balance. An 

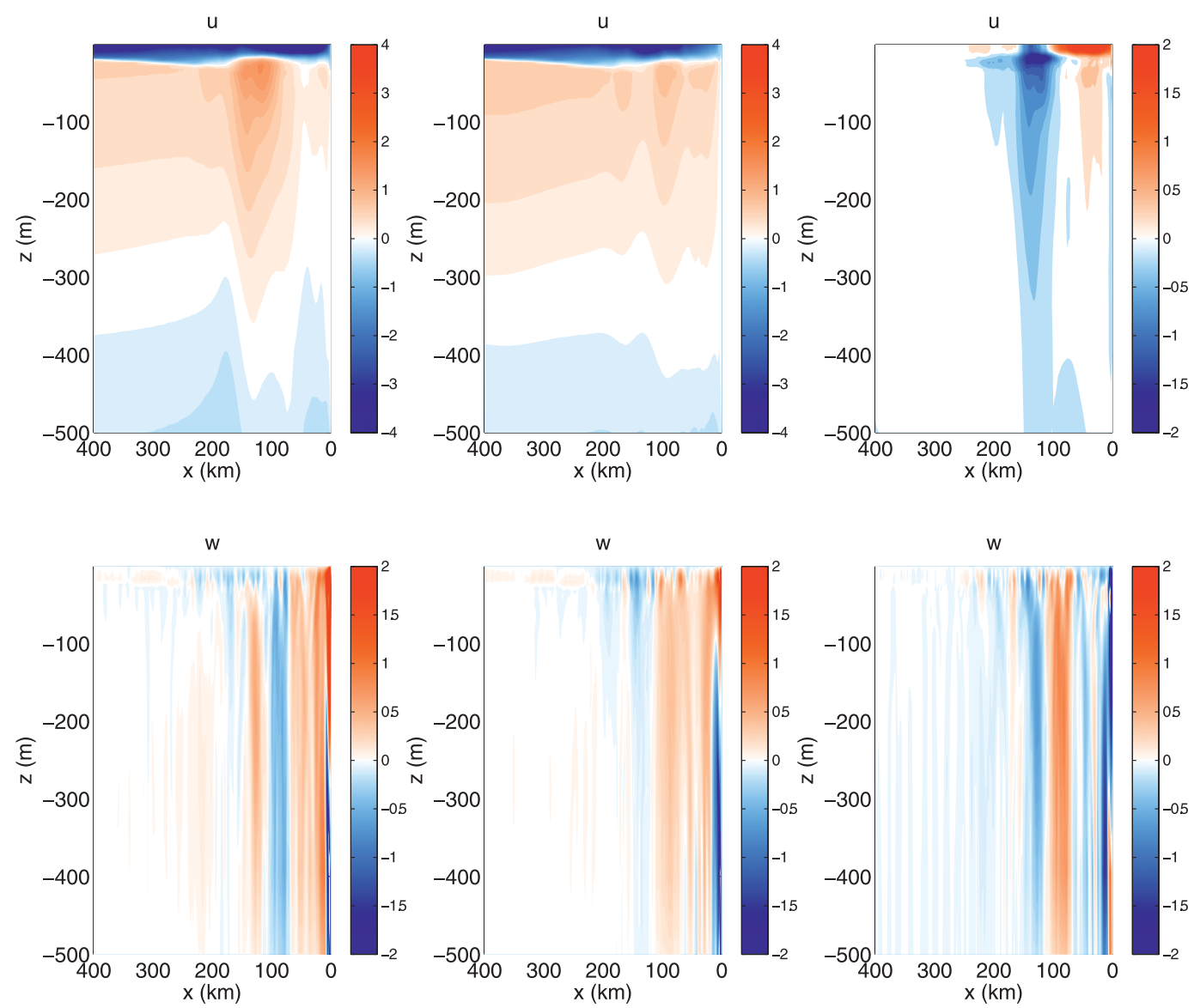

FIG. 6. As in Fig. 5, but for $u\left(\mathrm{~cm} \mathrm{~s}^{-1}\right)$ and $w\left(\mathrm{~m} \mathrm{day}^{-1}\right)$.

example is axisymmetric vortices with the equal and opposite-signed velocity and vorticity fields that have larger $T(r, z)$ and sea surface height (SSH) extrema with a smaller radial scale for the cyclonic vortex than for the anticyclonic one, with finite values for the vortex
Rossby number $($ Ro $=V / f L$; note that, in the quasigeostrophic limit, Ro $\rightarrow 0$, apart from sign, the shape difference between cyclones and anticyclones disappears; e.g., McWilliams 2006). These effects combine to enhance $|\nabla S S T|$ for cyclones. The spatial structures are
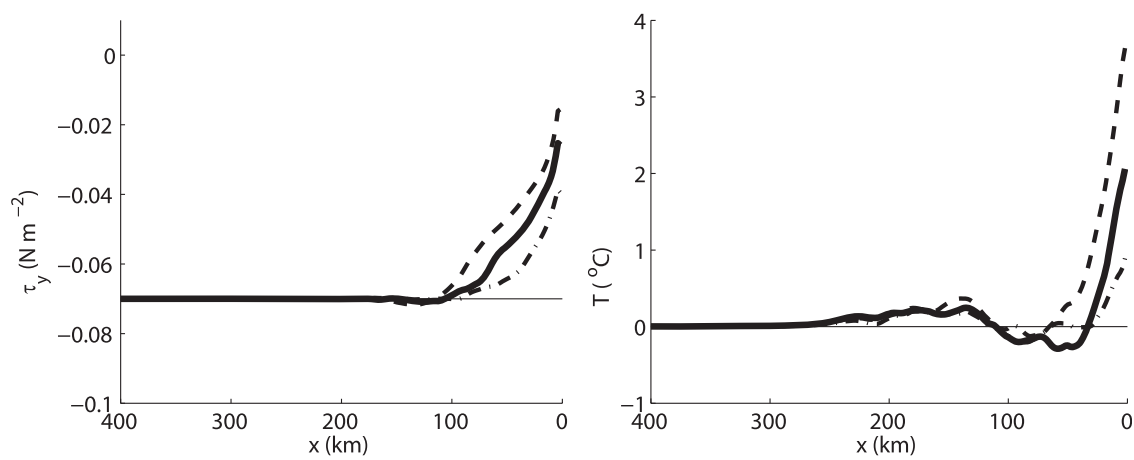

FIG. 7. (left) Meridional wind stress in the coupled simulations and (right) the SST differences between the coupled and uncoupled simulations, averaged alongshore and between days 40 and 80 . The solid line is the standard case, and the dashed and dotted lines are the DBL and HALF coupling coefficient sensitivity cases, respectively. The background meridional wind stress is $-0.07 \mathrm{~N} \mathrm{~m}^{-2}$. 


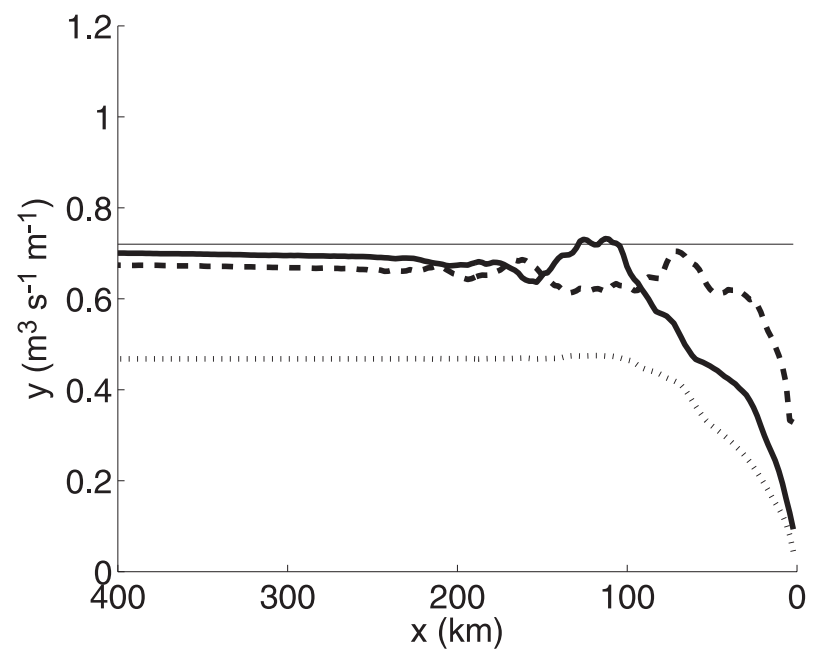

FIG. 8. Integrated mean upwelling $\int_{x}^{0} w\left(x, z_{0}\right) d x$ at $z_{0}=-20 \mathrm{~m}$ with alongshore and time averaging over days 40-80: offshore volume transport integrated vertically in the ocean surface layer in the uncoupled (dashed line) and coupled (solid line) simulations. For comparison, we plot the negative of the zonal Ekman transport determined from the background wind stress (i.e., $-\tau^{* y} / \rho_{w} f$; thin line) and the integrated Ekman suction computed from the wind stress curl divided by $f$ for the coupled simulation (dotted line).

illustrated for uncoupled-solution eddies in Fig. 11. They show the larger $T$ amplitude and the smaller $T$ and $\zeta$ spatial scale near the eddy center, as well as a deeper extension for the cyclone. The same relations also are found for typical cyclonic and anticyclonic Gulf Stream Rings (Auer 1987), although we have no argument for equating our upwelling system to the Gulf Stream dynamically.

For the coupled simulation, there is a striking shift to a much greater abundance of anticyclones (Fig. 9 and Table 1). Otherwise, there are only modest changes in the PDFs and population-averaged values resulting from coupling for most eddy properties, although these changes do have the effect of strengthening the anticyclones. We interpret the dominance of anticyclones with coupling as a consequence of two mechanisms. First, given their stronger SST gradients in the uncoupled eddy population, it is not surprising that the air-sea interaction is stronger in cyclones through the relations (8) and (9). In the coupled simulation, this causes local perturbations in the stress curl and divergence that act to force the eddy away from its axisymmetric shape (e.g., via Ekman pumping) and thereby disrupt its coherent evolution. This is illustrated in Fig. 12 for a particular eddy dipole pair. The SST amplitude is larger and the horizontal scale smaller for the cyclonic member. This induces appreciably larger wind stress curl and divergence over the cyclone than over the anticyclone; both fields show a two-lobed pattern that is related to a unidirectional wind over an isolated, circular SST anomaly. This implies a larger local wind stress perturbation over the cyclone that is a disruptive forcing for its further evolution. The second contributing mechanism is the general property that the eddy response to perturbations is much more dissipative for cyclones than anticyclones at finite Rossby numbers (Graves et al. 2006; Perret et al.
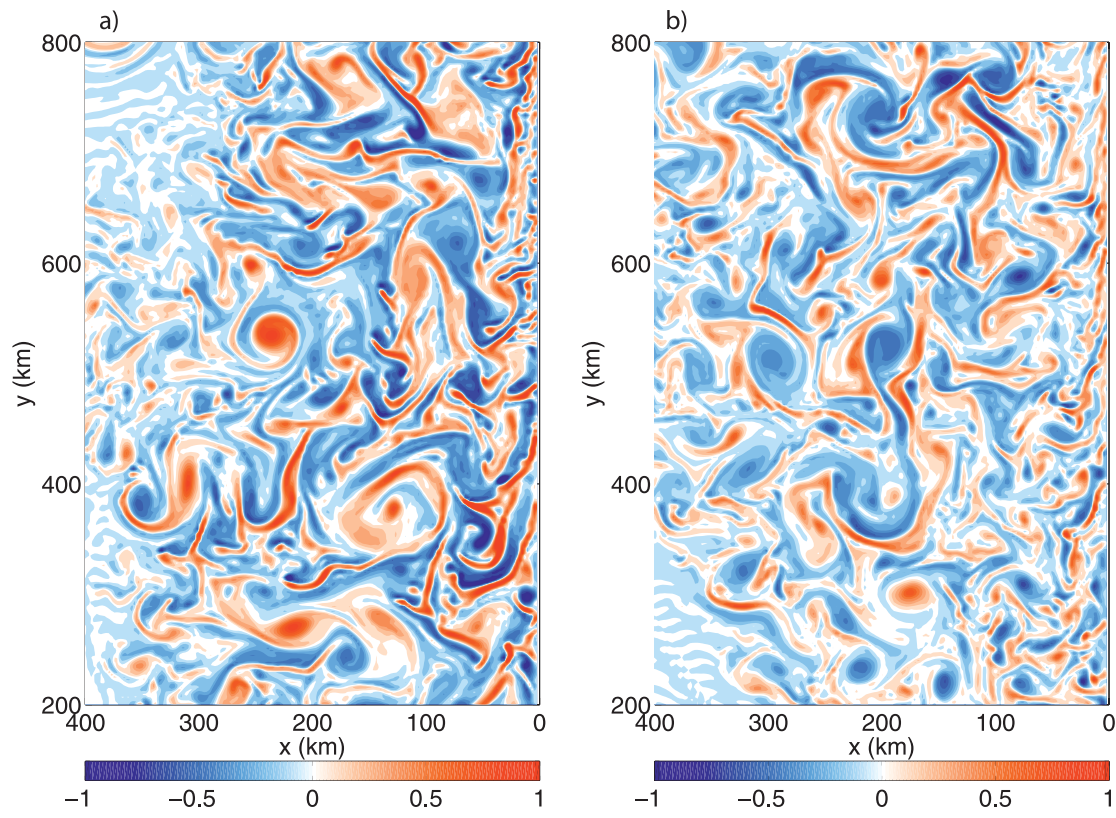

FIG. 9. Surface vorticity $\zeta(x, y)$ (normalized by $f$ ) on day 160: (a) uncoupled and (b) coupled simulations. 

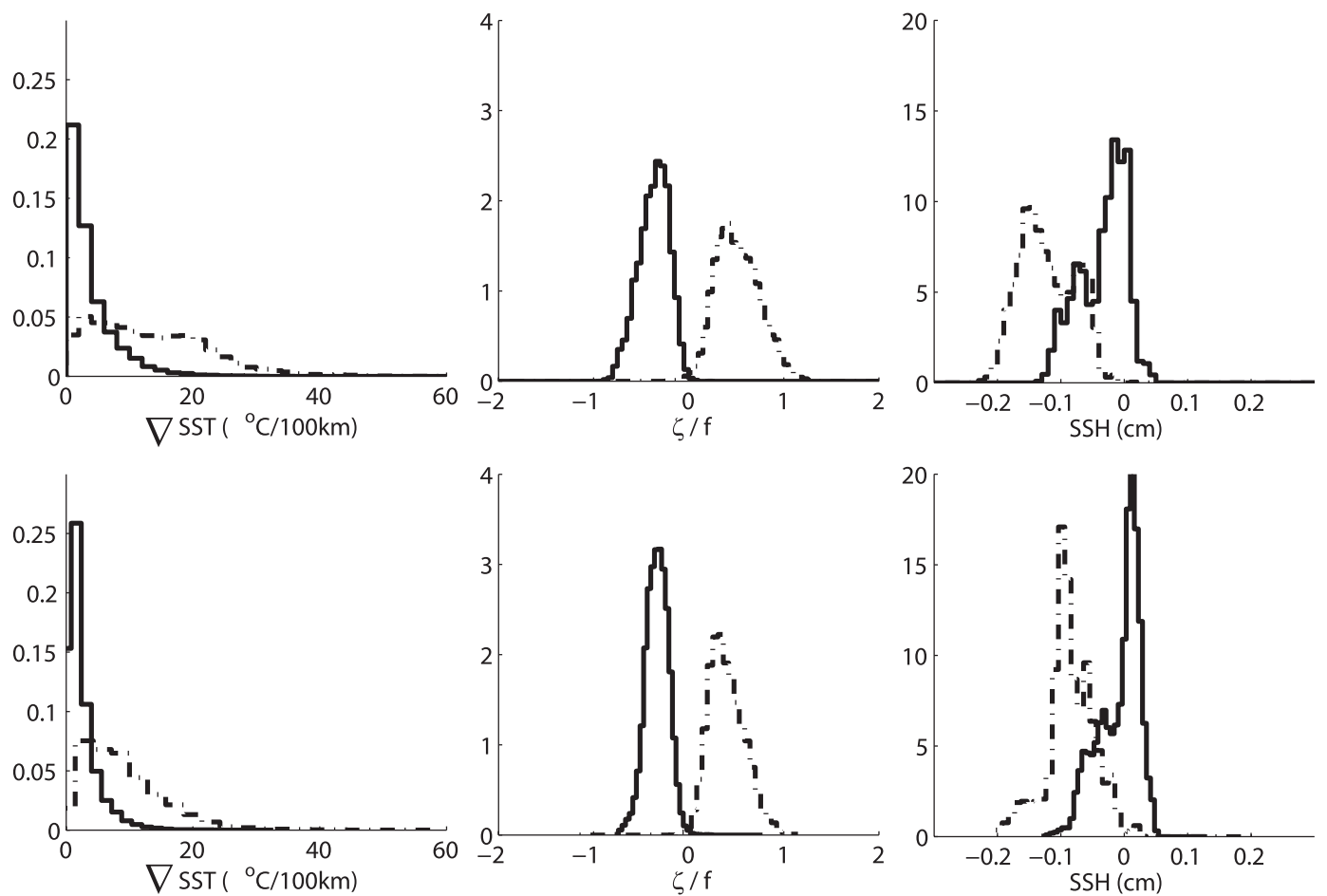

FIG. 10. Eddy-interior PDFs for (left) $|\nabla S S T|$, (middle) surface $\zeta / f$, and (right) SSH between days 100-200 for (top) uncoupled and (bottom) coupled simulations. The solid and dashed lines are for anticyclonic and cyclonic eddies, respectively. The interior is defined as the area inside a circle with the estimated eddy radius. The PDF is normalized such that the sum of the histogram values times the binning increment is unity; the binning increments are (left) (right) 2, 0.05, and 0.01

2006). These two mechanisms cause greater shape distortion and shorter lifetimes for the cyclonic eddies in the coupled simulation.

\section{Summary and prospect}

Hypothesizing the empirical coupling relations among SST gradients, wind direction, and the local curl and divergence of the wind stress, we find three important coupled mesoscale phenomena in an idealized subtropical eastern boundary current: first, the marine-terrestrial wind profile transition and reduced upwelling; second, the increase and broadening of the poleward undercurrent; and third, the eddy-scale coupling that leads to weaker eddy kinetic energy and more robust anticyclones relative to cyclones. Compared to an uncoupled solution, the coupled solution shows significant wind modifications in the nearshore regions that significantly alter the circulation: the nearshore equatorward wind stress weakens; hence the upwelling circulation weakens and the coastal zone SST is warmer; hence the subsurface temperature and alongshore currents change and the mesoscale instability weakens. This leads to further changes in the winds until mutual consistency is achieved. This process is potentially the resolution of the long- standing uncertainty about marine-terrestrial wind transition dynamics.

In this study, we only considered the empirical SSTwind stress relationship, whereas in reality the true coupling involves more atmospheric processes than those in the empirical coupling relations. For example, a passing

TABLE 1. Surface eddy statistics for the uncoupled and coupled simulations averaged between days 100 and 200 and over all eddies with a lifetime of at least 4 days. The population is the average number of eddies at any given time. The overbars are root-meansquare variations over the eddy interiors (i.e., within a circle of the eddy radius). The bottom three rows are eddy anomaly extrema relative to the time- and alongshore-mean fields at the eddy location.

\begin{tabular}{|c|c|c|c|c|}
\hline \multirow[b]{2}{*}{ Property } & \multicolumn{2}{|c|}{ Uncoupled } & \multicolumn{2}{|c|}{ Coupled } \\
\hline & Cyclonic & Anticyclonic & Cyclonic & Anticyclonic \\
\hline Population & 5.2 & 4.2 & 3.5 & 9.1 \\
\hline Radius (km) & 12.1 & 10.7 & 10.8 & 11.7 \\
\hline Lifetime (days) & 13.2 & 7.6 & 10.8 & 9.8 \\
\hline $\begin{array}{l}\overline{|\nabla S S T|} \\
\quad\left[{ }^{\circ} \mathrm{C}(100 \mathrm{~km})^{-1}\right]\end{array}$ & 15.9 & 5.4 & 11.0 & 3.6 \\
\hline $\begin{array}{l}\overline{|\operatorname{curl} \tau|} \\
\quad\left(10^{-7} \mathrm{~N} \mathrm{~m}^{-3}\right)\end{array}$ & - & - & 10.9 & 3.6 \\
\hline$\zeta^{\prime} / f_{0}$ & 0.72 & -0.43 & 0.59 & -0.40 \\
\hline $\mathrm{SST}^{\prime}\left({ }^{\circ} \mathrm{C}\right)$ & -1.97 & 0.70 & -1.06 & 0.54 \\
\hline $\mathrm{SSH}^{\prime}(\mathrm{cm})$ & -0.081 & 0.033 & -0.048 & 0.039 \\
\hline
\end{tabular}



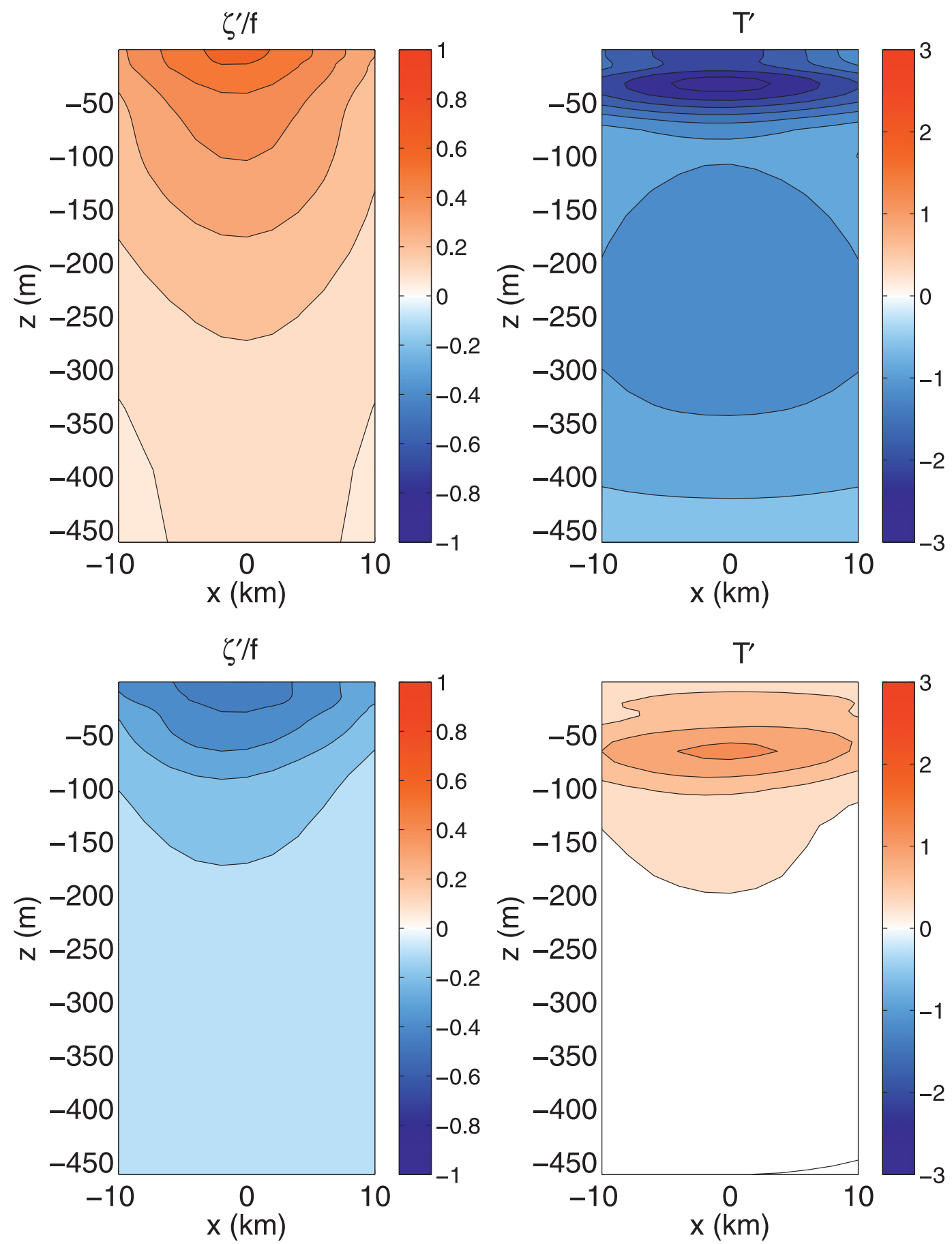

FIG. 11. Mean eddy structures for (left) $\zeta^{\prime} / f$ and (right) $T^{\prime}$ in the uncoupled simulation averaged over days 100-200 for (top) a cyclone and (bottom) an anticyclone. The prime denotes the difference compared to values at the same horizontal level in the neighborhood.

winter storm does not have time to fully adjust its surface winds to the underlying SST gradients, although it also may not have a strong influence on the oceanic currents; note also that SST gradients are generally weaker in winter (Castelao et al. 2006; Chelton et al. 2007a). An- other example, more germane to the coastal region, is the influence of coastal orography on adjacent marine winds (Enriquez and Friehe 1995; Dorman et al. 1999; Burk et al. 1999; Haack et al. 2001; Edwards et al. 2001, 2002; Perlin et al. 2004), quite apart from whatever SST-wind 

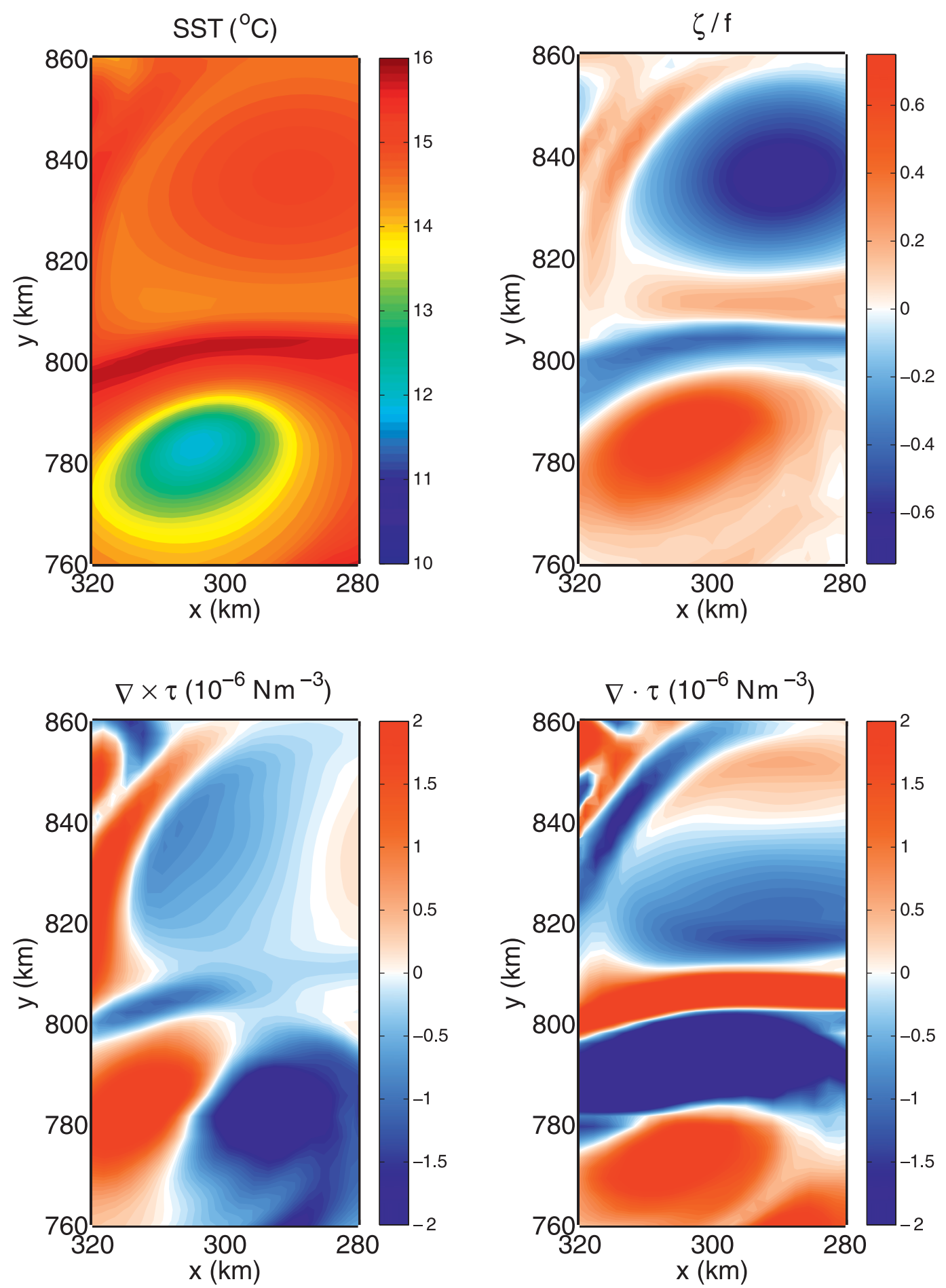

FIG. 12. An example of a cyclone-anticyclone pair in the coupled solution on day 140, showing SST, normalized surface vorticity, and wind stress curl and divergence. 
coupling is also acting. Therefore, further studies require a more dynamical atmospheric companion to the dynamical ocean (e.g., a fully coupled, regional oceanatmosphere model that resolves the coastal winds and circulation in both synoptic and climatological modes). Haack et al. (2008) have presented evidence that the ocean-atmosphere coupling that is the focus of this study may also play an important role in determining the structures of the SST and ocean circulation fields near major topographic features along the California and Oregon coasts.

In summary, our studies show a significant impact of the air-sea interaction on the coastal ocean, on both the mean circulation and the eddies. Given the magnitudes of these SST-induced perturbations of the surface wind stress field and the magnitudes or the associated Ekman upwelling feedback effects on the ocean, it would be very hard to imagine that this air-sea interaction is not an important component of the regional climate system. In addition, the air-sea interaction will play a key role in local ecosystem evolution and biogeochemical cycles because of the important role of the upwelling circulation in providing nutrients to the surface ocean.

Acknowledgments. We appreciate support from a grant from the Cooperative Institute for Oceanographic Satellite Studies at Oregon State University, Grants NNX08AI84G and NNX08AL91G from NASA, and Contracts 1283973 and 1283976 from the Jet Propulsion Laboratory for funding of Ocean Vector Winds Science Team activities. Comments and suggestions from two anonymous reviewers helped to improve the paper. Computations were made at the National Center for Supercomputing Applications.

\section{APPENDIX}

\section{Eddy Detection and Tracking Procedure}

Automated eddy detection and tracking is based on $Q$, the second invariant of the horizontal velocity gradient tensor. Eddies are identified by closed contours of $Q>0$, inside of which rotation dominates deformation. Following Isern-Fontanet et al. (2003), we define

$$
Q=-\left(\frac{\partial u}{\partial x}\right)^{2}-\left(\frac{\partial v}{\partial x}\right)\left(\frac{\partial u}{\partial y}\right)
$$

where $u$ and $v$ are eastward and northward velocities, respectively. Except for a change of sign and a factor of 4 , $Q$ corresponds to the Okubo-Weiss parameter (Okubo 1970; Weiss 1991), which takes the following form for horizontally nondivergent flows (Chelton et al. 2007b):

$$
W=4\left[\left(\frac{\partial u}{\partial x}\right)^{2}+\left(\frac{\partial v}{\partial x}\right)\left(\frac{\partial u}{\partial y}\right)\right]
$$

In the present study, the closed contours of $Q$ in the range of 4-50 $\times 10^{-11} \mathrm{~s}^{-2}$ were used to define eddies at surface, but we get essentially equivalent results if we test on $W$ with values 4 times larger. We use a range of values instead of a threshold [as employed in IsernFontanet et al. (2003) and Chelton et al. (2007b)] to detect eddies, irrespective of their relative strength. The $Q$ field is smoothed with 10 applications of a 2D Hanning smoother to diminish the spatial noise. Otherwise, the present method is similar to that used by Chelton et al. (2007b) for tracking eddies on successive altimetry maps. The center of the eddy is defined as that of the circle fitted to the closed contour of $Q$. The vorticity sign at the center point determines the polarity: cyclonic or anticyclonic. The radius of the eddy is defined as the minimum distance between the identified center and outermost closed contour of the vorticity with the same polarity as the center, thus ensuring that the eddy interior inside this radius has a vorticity of only one sign. Only those eddies with a minimum radius of $8 \mathrm{~km}$ (nearly 4 times the grid resolution) are counted. Eddies are tracked by comparing eddy centers in two consecutive time levels $\left(t_{n}\right.$ and $\left.t_{n+1}\right)$ of model output (2-day averages). A given eddy at time level $t_{n}$ is tracked at time level $t_{n+1}$ by finding the closest eddy center at $t_{n+1}$. To avoid switching between tracks, an additional condition requires that the distance between eddy centers at $t_{n}$ and $t_{n+1}$ should be less than the maximum value of the eddy radius among these two time levels. Only those eddies that are tracked for at least 4 days are counted.

\section{REFERENCES}

Auer, S. J., 1987: Five-year climatological survey of the Gulf Stream system and its associated rings. J. Geophys. Res., 92, $11709-11726$.

Burk, S., T. Haack, and R. M. Samelson, 1999: Mesoscale simulation of supercritical, subcritical, and transcritical flow along coastal topography. J. Atmos. Sci., 56, 2780-2795.

Capet, X. J., P. Marchesiello, and J. C. McWilliams, 2004: Upwelling response to coastal wind profiles. Geophys. Res. Lett., 31, L13311, doi:10.1029/2004GL020123.

_ J. C. McWilliams, M. J. Molemaker, and A. F. Shchepetkin, 2008: Mesoscale to submesoscale transition in the California Current System: Flow structure, eddy flux, and observational tests. J. Phys. Oceanogr., 38, 29-43.

Castelao, R. M., T. P. Mavor, J. A. Barth, and L. C. Breaker, 2006: Sea surface temperature fronts in the California Current System from geostationary satellite observations. J. Geophys. Res., 111, C09026, doi:10.1029/2006JC003541.

Chelton, D. B., 1984: Seasonal variability of alongshore geostrophic velocity off central California. J. Geophys. Res., 89, 3473-3486. 
, and Coauthors, 2001: Observations of coupling between surface wind stress and sea surface temperature in the eastern tropical Pacific. J. Climate, 14, 1479-1498.

—, M. G. Schlax, M. H. Freilich, and R. Milliff, 2004: Satellite measurements reveal persistent small-scale features in ocean winds. Science, 303, 978-983.

—_ _ - and R. M. Samelson, 2007a: Summertime coupling between sea surface temperature and wind stress in the California Current System. J. Phys. Oceanogr., 37, 495-517.

,,--- , and R. A. de Szoeke, 2007b: Global observations of large oceanic eddies. Geophys. Res. Lett., 34, L15606, doi:10.1029/2007GL030812.

Chen, D., W. T. Liu, W. Tang, and Z. Wang, 2003: Air-sea interaction at an oceanic front: Implication for frontogenesis and primary production. Geophys. Res. Lett., 30,1745, doi:10.1029/ 2003 GL017536.

Dong, C., and L. Oey, 2005: Sensitivity of coastal currents near Point Conception to forcing by three different winds: ECMWF, COAMPS, and blended SSM/I-ECMWF-buoy winds. J. Phys. Oceanogr., 35, 1229-1244.

—_, and J. C. McWilliams, 2007: A numerical study of island wakes in the Southern California Bight. Cont. Shelf Res., 27, 1231-1248.

Dorman, C. E., D. P. Rogers, W. Nuss, and W. T. Thompson, 1999: Adjustment of the summer marine boundary layer around Pt. Sur, California. Mon. Wea. Rev., 127, 2143-2159.

—, E. P. Dever, J. Largier, and D. Koracin, 2006: Buoy measured wind, wind stress and wind stress curl over the shelf off Bodega Bay. Deep-Sea Res. II, 53, 2850-2864.

Edwards, K. A., A. M. Rogerson, C. D. Winant, and D. P. Rogers, 2001: Adjustment of the marine atmospheric boundary layer to a coastal cape. J. Atmos. Sci., 58, 1511-1528.

— D. P. Rogers, and C. E. Dorman, 2002: Adjustment of the marine atmospheric boundary layer to the large-scale bend in the California coast. J. Geophys. Res., 107, 3213, doi:10.1029/ 2001JC000807.

Enriquez, A. G., and C. A. Friehe, 1995: Effects of wind stress and wind stress curl variability on coastal upwelling. J. Phys. Oceanogr., 25, 1651-1671.

Estrade, P., P. Marchesiello, A. C. De Verdiere, and C. Roy, 2008: Cross-shelf structure of coastal upwelling: A two-dimensional extension of Ekman's theory and a mechanism for inner shelf upwelling shut down. J. Mar. Res., 66, 589-616.

Gan, J., and J. S. Allen, 2005: Modelling upwelling circulation off the Oregon coast. J. Geophys. Res., 110, C10S07, doi:10.1029/ 2004JC002692.

Graves, L. P., J. C. McWilliams, and M. T. Montgomery, 2006: Vortex evolution due to straining: A mechanism for dominance of strong, interior anticyclones. Geophys. Astrophys. Fluid Dyn., 100, 151-183.

Haack, T., S. D. Burk, C. Dorman, and D. Rogers, 2001: Super critical flow interaction within the Cape Blanco-Cape Mendocino orographic complex. Mon. Wea. Rev., 129, 688-708.

—, D. Chelton, J. Pullen, J. Doyle, and M. Schlax, 2008: Air-sea interaction from U. S. West Coast summertime forecasts. J. Phys. Oceanogr., 38, 2414-2437.

Hickey, B., and N. Pola, 1983: The seasonal alongshore pressure gradient on the west coast of the United States. J. Geophys. Res., 88, 7623-7633.
Isern-Fontanet, J., E. García-Ladona, and J. Font, 2003: Identification of marine eddies from altimetric maps. J. Phys. Oceanogr., 20, 772-778.

Kirsch, A., 1996: An Introduction to the Mathematical Theory of Inverse Problems. Springer, $283 \mathrm{pp}$.

Large, W. G., J. C. McWilliams, and S. C. Doney, 1994: Oceanic vertical mixing: A review and a model with a nonlocal boundary layer parameterization. Rev. Geophys., 32, 363-403.

Li, Z., Y. Chao, and J. C. McWilliams, 2006: Computation of the streamfunction and velocity potential for limited and irregular domains. Mon. Wea. Rev., 134, 3384-3394.

Lindzen, R. S., and S. Nigam, 1987: On the role of sea surface temperature gradients in forcing low-level winds and convergence in the tropics. J. Atmos. Sci., 44, 2418-2436.

Marchesiello, P., J. C. McWilliams, and A. F. Shchepetkin, 2001: Open boundary conditions for long-term integration of regional ocean models. Ocean Modell., 3, 1-10.

,-- , and $—$, 2003: Equilibrium structure and dynamics of the California Current System. J. Phys. Oceanogr., 33, 753-783.

McWilliams, J. C., 2006: Fundamentals of Geophysical Fluid Dynamics. Cambridge University Press, 249 pp.

Moloney, E. D., and D. B. Chelton, 2006: SST influence on surface wind stress in climate models. J. Climate, 19, 2743-2762.

Okubo, A., 1970: Horizontal dispersion of floatable particles in the vicinity of velocity singularities such as convergences. DeepSea Res., 17, 445-454.

Perlin, N., R. M. Samelson, and D. B. Chelton, 2004: Scatterometer and model wind and wind stress in the Oregon-California coastal zone. Mon. Wea. Rev., 132, 2110-2129.

_ E. D. Skyllingstad, R. M. Samelson, and P. L. Barbour, 2007: Numerical simulation of air-sea coupling during coastal upwelling. J. Phys. Oceanogr., 37, 837-854.

Perret, G., A. Stegner, M. Farge, and T. Pichon, 2006: Cycloneanticyclone asymmetry of large-scale wakes in the laboratory. Phys. Fluids, 18, 036603, doi:10.1063/1.2179387.

Seo, H., A. J. Miller, and J. O. Roads, 2007: The Scripps Coupled Ocean-Atmosphere Regional (SCOAR) model, with applications in the eastern Pacific sector. J. Climate, 20, 381-402.

Shchepetkin, A. F., and J. C. McWilliams, 1998: Quasi-monotone advection schemes based on explicit locally adaptive dissipation. Mon. Wea. Rev., 126, 1541-1580.

—_, and — , 2005: The Regional Oceanic Modeling System (ROMS): A split-explicit, free-surface, topography-followingcoordinate oceanic model. Ocean Modell., 9, 347-404.

Small, R. J., and Coauthors, 2008: Air-sea interaction over ocean fronts and eddies. Dyn. Atmos. Oceans, 45, 274-319, doi:10.1016/ j.dynatmoce.2008.01.001.

Spall, M. A., 2007: Effect of sea surface temperature-wind stress coupling on baroclinic instability in the ocean. J. Phys. Oceanogr., 37, 1092-1097.

Tikhonov, A. N., and V. Arsenin, 1977: Solution of Ill-Posed Problems. Winston and Sons, $224 \mathrm{pp}$.

Weiss, J., 1991: The dynamics of enstrophy transfer in two dimensional hydrodynamics. Physica D., 48 (2-3), 273-294.

Welander, P., 1957: Wind action in a shallow sea: Some generalizations of Ekman's theory. Tellus, 9, 45-52. 